ARTICLE

Received 25 Nov 2016 | Accepted 12 May 2017 | Published 26 Jun 2017

DOI: $10.1038 /$ ncomms15909

OPEN

\title{
Uniform electroactive fibre-like micelle nanowires for organic electronics
}

Xiaoyu Li ${ }^{1, *},{ }^{\dagger}$, Piotr J. Wolanin ${ }^{1,2, \star}$, Liam R. MacFarlane ${ }^{1}$, Robert L. Harniman ${ }^{1}$, Jieshu Qian ${ }^{1, \dagger}$, Oliver E.C. Gould ${ }^{1,2}$, Thomas G. Dane ${ }^{3}$, John Rudin ${ }^{4}$, Martin J. Cryan ${ }^{5}$, Thomas Schmaltz ${ }^{6}$, Holger Frauenrath ${ }^{6}$, Mitchell A. Winnik ${ }^{7}$, Charl F.J. Faul ${ }^{1} \&$ lan Manners ${ }^{1}$

Micelles formed by the self-assembly of block copolymers in selective solvents have attracted widespread attention and have uses in a wide variety of fields, whereas applications based on their electronic properties are virtually unexplored. Herein we describe studies of solution-processable, low-dispersity, electroactive fibre-like micelles of controlled length from $\pi$ conjugated diblock copolymers containing a crystalline regioregular poly(3-hexylthiophene) core and a solubilizing, amorphous regiosymmetric poly(3-hexylthiophene) or polystyrene corona. Tunnelling atomic force microscopy measurements demonstrate that the individual fibres exhibit appreciable conductivity. The fibres were subsequently incorporated as the active layer in fieldeffect transistors. The resulting charge carrier mobility strongly depends on both the degree of polymerization of the core-forming block and the fibre length, and is independent of corona composition. The use of uniform, colloidally stable electroactive fibre-like micelles based on common $\pi$-conjugated block copolymers highlights their significant potential to provide fundamental insight into charge carrier processes in devices, and to enable future electronic applications.

\footnotetext{
${ }^{1}$ School of Chemistry, University of Bristol, Cantock's Close, Bristol BS8 1TS, UK. ${ }^{2}$ Bristol Centre for Functional Nanomaterials, University of Bristol, Tyndal Avenue, Bristol BS8 1TL, UK. ${ }^{3}$ European Synchrotron Radiation Facility, BP 220, Grenoble F-38043, France. ${ }^{4}$ Folium Optics Ltd, Unit 28, Cooper Road, Thornbury, Bristol BS35 3UP, UK. ${ }^{5}$ Department of Electrical and Electronic Engineering, University of Bristol, Woodland Road, Bristol BS8 1UB, UK. ${ }^{6}$ Laboratory of Macromolecular and Organic Materials, Institute of Materials, Ecole Polytechnique Fédérale de Lausanne (EPFL), EPFL-STI-IMX-LMOM, Station 12, 1015 Lausanne, Switzerland. ${ }^{7}$ Department of Chemistry, University of Toronto, Toronto, Ontario, Canada M5S 3H6. ${ }^{*}$ These authors contributed equally to this work. $\uparrow$ Present addresses: Department of Polymer Materials, School of Material Science and Technology, Beijing Institute of Technology, Beijing 100081, China (X.L.); School of Environmental and Biological Engineering, Nanjing University of Science and Technology, 200 Xiao Ling Wei, Nanjing 210094, China (J.Q.). Correspondence and requests for materials should be addressed to C.F.J.F. (email: charl.faul@bristol.ac.uk) or to I.M.

(email: ian.manners@bristol.ac.uk).
} 
T he self-assembly of block copolymers (BCPs) in solvents selective for one segment offers an important and well-developed method for the formation of spherical and cylindrical (or fibre-like) micelles and vesicles ${ }^{1}$. The resulting nanostructures show colloidal stability due to the presence of the solvent swollen corona and have been exploited for a variety of uses including the delivery of therapeutic cargoes in nanomedicine $^{2}$, as additives for friction reduction ${ }^{3}$, fillers for composite reinforcement ${ }^{4}$ or for the formation of nanoscopic arrays using optical tweezers ${ }^{5}$. However, although recent advances have described examples of fibre-like micelles with novel photophysical characteristics, 6 , their assembly into complex semiconducting particles, bundles and branched superstructures $^{8-11}$, and their fabrication of coaxial nanowires with quantum dots ${ }^{12,13}$, ordered two-dimensional assemblies at interfaces $^{14}$ and solar cells ${ }^{15}$, the evaluation of their potential as functional electroactive materials in devices is virtually unexplored ${ }^{14,15}$; specifically, uniform samples of low length dispersity have not been investigated.

As a consequence of their low density and solution processablity, $\pi$-conjugated semiconducting polymers possess many advantages over traditional semiconductors and metals, leading to their extensive exploitation in photovoltaics ${ }^{16-18}$, light-emitting devices ${ }^{19-21}$, field-effect transistors ${ }^{22-24}$ and sensors $^{25,26}$. Fibres fabricated from solely $\pi$-conjugated homopolymers have been studied in particular detail and high charge carrier mobilities $(\mu)$ have been reported ${ }^{27-29}$. However, these one-dimensional nanostructures exhibit limited colloidal stability and access to uniform samples of controlled length that allows optimization for different applications remains a severe challenge ${ }^{30,31}$.

Herein we report the exploration of the potential of colloidally stable fibre-like BCP micelles with precisely controllable length, low dispersities and a $\pi$-conjugated core both to provide insight into the factors that influence device performance and also to enable wider organic electronic applications.

\section{Results}

Preparation of uniform fibre-like micelles. The BCPs used to prepare the fibre-like micelles used in this study possessed a crystallizable core-forming regioregular poly(3-hexylthiophene) $(r r \mathrm{P} 3 \mathrm{HT})$ block $^{6-10}$ and a solubilizing, amorphous coronal block. To allow us to probe the influence of the corona on charge transport, two different coronas were investigated: regiosymmetric poly(3-hexylthiophene) (rsP3HT) $)^{21,32-34}$ and polystyrene (PS). The $r r \mathrm{P} 3 \mathrm{HT}-b-r s \mathrm{P} 3 \mathrm{HT}$ materials were prepared via sequential Grignard metathesis (GRIM) polymerization (Supplementary Fig. 1a) ${ }^{35,36}$, whereas the $r r$ P3HT- $b$-PS BCPs were synthesized by a $\mathrm{Cu}$-catalysed azide-alkyne cycloaddition reaction, using azideterminated PS and alkyne end-functionalized $r$ P $3 \mathrm{HT}$ homopolymers ${ }^{37,38}$. The sequential GRIM polymerization has been extensively explored and has been widely used to synthesize thiophene-based all-conjugated BCPs. ${ }^{910,35,36}$ The characteristics of $r r \mathrm{P}_{3} \mathrm{HT}_{106}-b-r s \mathrm{P}^{2} \mathrm{HT}_{47}, \quad r r \mathrm{P}_{3} \mathrm{HT}_{48}-b-r s \mathrm{P}_{3} \mathrm{HT}_{43}, \quad r r \mathrm{P}^{2} \mathrm{HT}_{54}-b$ $\mathrm{PS}_{44}, \quad r r \mathrm{P}_{3} \mathrm{HT}_{70}-b-\mathrm{PS}_{197}$ and homopolymer $\quad r r \mathrm{P}_{3} \mathrm{HT}_{48}$ (the subscripts represent the degree of polymerization (DP) of each block) are summarized in Supplementary Table 1 and Supplementary Figs 1-3.

Uniform fibre-like micelles were fabricated from the $r r \mathrm{P} 3 \mathrm{HT}-b-r s \mathrm{P} 3 \mathrm{HT} \mathrm{BCPs}$ by the living crystallization-driven selfassembly (CDSA) method, which involves epitaxial growth of BCP unimers (molecularly dissolved BCP) from seed micelles ${ }^{37-}$ 42. A modification of CDSA, known as thermally induced selfseeding, was used in this study to facilitate the formation of a $r r \mathrm{P} 3 \mathrm{HT}$ core with a minimized number of defects ${ }^{38,41,42}$. In this solution-based process, short fibre-like micelles are heated to different temperatures. Regions of lower core crystallinity dissolve to leave crystalline seeds; on cooling to room temperature, the dissolved BCP adds to the seeds to form elongated fibres. As the percentage of remaining seeds decreases with increased temperature ${ }^{43-46}$, the length of the resulting fibres can be controlled precisely to yield fibres with relatively low-length dispersities.

In this study, polydisperse fibre-like micelles were initially prepared by dissolution of the BCPs in anisole at $80^{\circ} \mathrm{C}$ for $1 \mathrm{~h}$ and subsequent cooling to room temperature over $6 \mathrm{~h}\left(23^{\circ} \mathrm{C}\right.$; Fig. 1a, Step (1)). Shown in Fig. 1b,c are the transmission electron microscopy (TEM) images of the resulting multi-micrometre-long fibres, of which lengths were often larger than the TEM grid used for imaging $(\sim 10 \mu \mathrm{m} \times 10 \mu \mathrm{m})$. The length distribution was broad and the polydispersity of the $r r \mathrm{P}^{2} \mathrm{HT}_{106}-b-r s \mathrm{P}_{3} \mathrm{HT}_{47}$ fibres $\left(L_{\mathrm{w}} / L_{\mathrm{n}}\right.$, where $L_{\mathrm{w}}$ is the weight-average length and $L_{\mathrm{n}}$ the number average length) was $\sim 2.4$ and $\sim 2.0$ for $r r \mathrm{P}_{3} \mathrm{HT}_{48}-b$-rs $\mathrm{P}_{3} \mathrm{HT}_{43}$ fibres. Despite large differences in the DP of the $r r$ P3HT block, the fibres formed from the two BCPs were found to be very similar in core width $(15 \pm 2 \mathrm{~nm}$ and $16 \pm 1 \mathrm{~nm}$ as determined from TEM images for fibres from $r r \mathrm{P}_{3} \mathrm{HT}_{48}-b-r s \mathrm{P} \mathrm{HT}_{43}$ and $r r \mathrm{P}_{3} \mathrm{HT}_{106}-b-r s \mathrm{P}_{3} \mathrm{HT}_{47}$, respectively). This implies that the $\mathrm{P} 3 \mathrm{HT}$ chains in a $r r \mathrm{P}^{2} \mathrm{HT}_{48}-b$ $r s \mathrm{P}_{3} \mathrm{HT}_{43}$ fibre are almost fully extended, whereas chain folding should occur in the core of $r r \mathrm{P}_{3} \mathrm{HT}_{106}-b$-rs $\mathrm{P}_{3} \mathrm{HT}_{47}$ fibres ${ }^{47,48}$ (see 'Additional discussion on chain folding in the fibre core' in the Supplementary Information). The less dense, amorphous $r s \mathrm{P} 3 \mathrm{HT}$ corona was only visible after staining with $\mathrm{RuO}_{4}$ (Supplementary Fig. 4a). The width of the $r r \mathrm{P}^{2} \mathrm{HT}_{106}-b$ $r s \mathrm{P}^{\mathrm{HTT}}{ }_{47}$ fibres increased to $26 \pm 3 \mathrm{~nm}$ after staining, clearly indicating the existence of an outer corona layer. The crystalline $r r$ P3H cores were characterized by photoluminescence and solution ultraviolet-visible absorbance spectroscopy, whereas $r s \mathrm{P} 3 \mathrm{HT}$ is completely amorphous and soluble in anisole (see Supplementary Figs 5,6 and 'Additional discussion on the ultraviolet-visible and photoluminescence spectra' in the Supplementary Information). The crystalline $r r \mathrm{P} 3 \mathrm{HT}$ core is lamellar and of type I polymorph, as determined by thin-film grazing incidence wide-angle X-ray scattering (GIWAXS) measurements (Supplementary Fig. 7 and 'Additional comments on GIWAXS data' in the Supplementary Information). Based on the results from TEM, atomic force microscopy (AFM) and GIWAXS, these fibres adopt a ribbon-like structure, with the $r s \mathrm{P} 3 \mathrm{HT}$ corona chain only present on the sides of the fibres (see 'Additional comments on GIWAXS data' in the Supplementary Information and Supplementary Fig. 4).

The self-seeding process involved two steps. Taking the case of $r r \mathrm{P}_{3} \mathrm{HT}_{106}-b-r s \mathrm{P}_{3} \mathrm{HT}_{47}$, first, the pristine polydisperse fibre-like micelles were fragmented by ultrasonication in anisole at $0{ }^{\circ} \mathrm{C}$ for $1 \mathrm{~h}$ (Fig. 1a, Step (2), Supplementary Fig. 8a) to yield uniform short fibres. In the second step, the solutions of short fibres were thermally annealed at a desired temperature between $56^{\circ} \mathrm{C}$ and $64^{\circ} \mathrm{C}$ for $1 \mathrm{~h}$, followed by gradual cooling to $23^{\circ} \mathrm{C}$ over several hours (Fig. 1a, Step (3)). The maximum annealing temperature for self-seeding experiments was $c a .64^{\circ} \mathrm{C}$. Above this temperature, all of the short fibre-like micelles dissolved and, in the absence of remaining seeds, no length control was evident, as samples cooled to $23^{\circ} \mathrm{C}$ contained mixtures of both very long and short fibres. The lengths $\left(L_{\mathrm{n}}\right.$ and $\left.L_{\mathrm{w}}\right)$ of the resultant uniform fibres were determined from the TEM images and the s.d. $(\sigma)$ calculated. The samples annealed at $64^{\circ} \mathrm{C}$ (Fig. 1f) produced the longest fibres with a narrow length distribution $\left(L_{\mathrm{n}}=952 \mathrm{~nm}\right.$, $L_{\mathrm{w}} / L_{\mathrm{n}}=1.10$ ). The length information for samples at different annealing temperatures is summarized in Fig. $1 \mathrm{~g}$ (also Supplementary Fig. 8 and Supplementary Table 2). Based on 

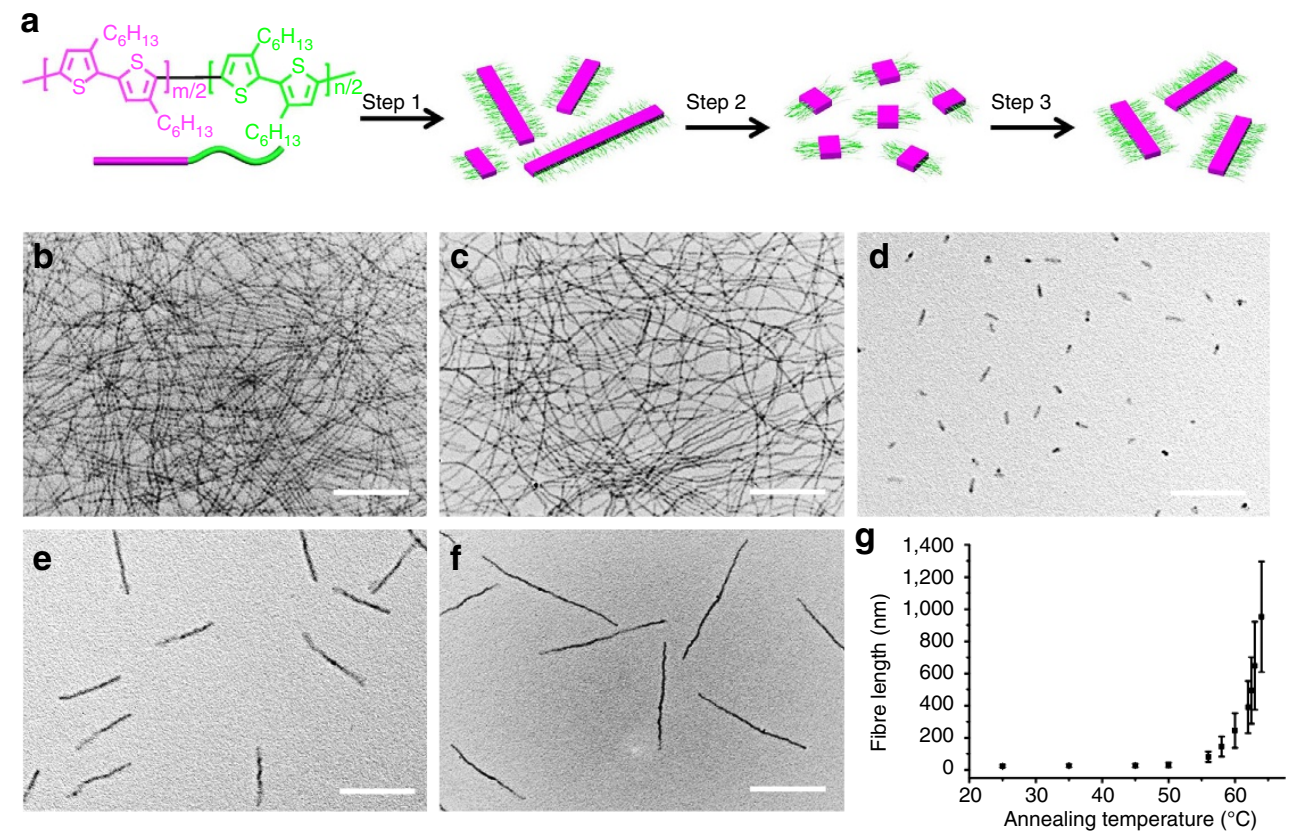

Figure 1 | Fibres from $r$ rP3HT-b-rsP3HT. (a) Chemical structure of rrP3HT-b-rsP3HT diblock copolymer and the schematic illustration of Step 1 ,

self-assembly of rrP3HT-b-rsP3HT to form fibres in anisole; Step 2, fragmentation of the fibres; and Step 3, thermal annealing to form uniform fibres. TEM images of the unfragmented fibres from (b) $r r \mathrm{P}_{3} \mathrm{HT}_{48}-b-r s \mathrm{P}_{3} \mathrm{HT}_{43}$ and (c) $r r \mathrm{P}_{3} \mathrm{HT}_{106}-b$-rsP3 $3 \mathrm{HT}_{47}$, which were obtained by directly dispersing the polymer solid in anisole at $0.1 \mathrm{mg} \mathrm{ml}^{-1}$ at $80^{\circ} \mathrm{C}$ for $1 \mathrm{~h}$ and then slowly cooling to $23^{\circ} \mathrm{C}$. Uniform fibres from rrP3 $\mathrm{HT}_{106}-b$-rs $\mathrm{P}_{3} \mathrm{HT}_{47} \mathrm{Prepared}$ by subjecting anisole solutions of fibres $\left(0.1 \mathrm{mg} \mathrm{ml}^{-1}\right)$ to ultrasonication at $0^{\circ} \mathrm{C}$ for $1 \mathrm{~h}$, followed by thermal annealing at (d) $56.0^{\circ} \mathrm{C},(\mathbf{e}) 62.5^{\circ} \mathrm{C},(\mathbf{f}) 64.0^{\circ} \mathrm{C}$ for $30 \mathrm{~min}$ and then slow (ca. $6 \mathrm{~h}$ ) cooling to $23^{\circ} \mathrm{C}$. Scale bars, $500 \mathrm{~nm}$. (g) Plot of the $L_{n}$ of the $\mathrm{rrP} \mathrm{HT}_{106}-b$-rsP3HT $\mathrm{H}_{47}$ fibres versus self-seeding temperatures.

a

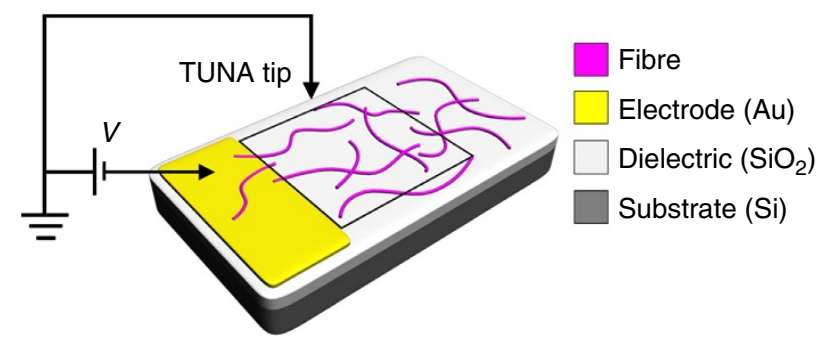

b

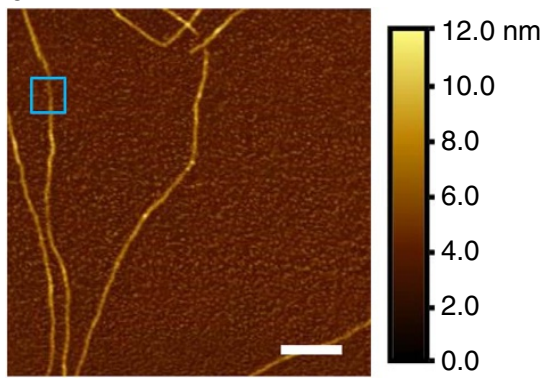

c

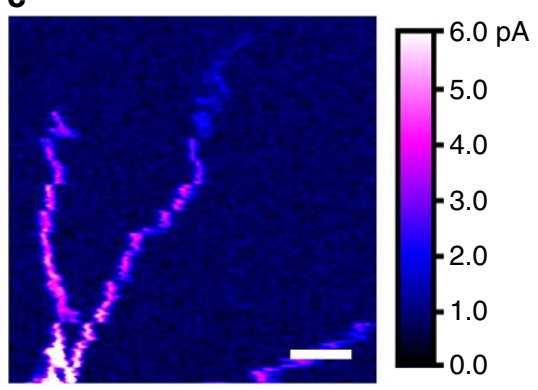

Figure 2 | Tunnelling atomic force (TUNA) microscopy image of fibres. (a) Schematic of the TUNA experiment (the black square indicates where the image was obtained). (b) Height and (c) TUNA contact current images of unfragmented rrP3HT $106-b$-rsP3HT 47 fibres $\left(L_{n}>10 \mu m\right)$. Scale bars, $500 \mathrm{~nm}$. The fibres visible in $\mathbf{b}$ but not in $\mathbf{c}$ were disconnected from the gold electrode (break in the fibre, and thus the connection to the gold electrode, indicated in the blue box). The sub-monolayer films were prepared by spin-coating of $0.1 \mathrm{mg} \mathrm{ml}^{-1}$ fibre dispersions at 3,000 r.p.m. The gold electrode is positioned at the bottom of the AFM images and not imaged to avoid short-circuiting; see Supplementary Fig. 10a,b for an AFM height image showing the electrode position, as well as the TUNA contact current image at full scale, respectively.

the initial length of the short fibres and the final length of fibres after annealing, we calculated the fraction of surviving fragments at each annealing temperature. As shown in Supplementary Fig. 8j, for the investigated temperature range, the fraction of surviving seeds decreased exponentially with increasing temperature, a key characteristic of a self-seeding process ${ }^{41,49}$. This protocol thus allowed the formation of fibres ranging in length from below $30 \mathrm{~nm}$ to over $950 \mathrm{~nm}$ with low polydispersities $\left(L_{\mathrm{w}} / L_{\mathrm{n}}<1.20\right)$. 
During this process, the peak intensity at $560 \mathrm{~nm}$ in ultravioletvisible spectrum increased, indicating a higher crystallinity of the rrP3HT block in the core ${ }^{50}$ (Supplementary Fig. 6e). For $r r \mathrm{P} \mathrm{HT}_{48}-b-r s \mathrm{P}_{3} \mathrm{HT}_{43}$ fibres, the same experimental procedures were applied and similar results were obtained (Supplementary Fig. 9 and Supplementary Table 2).

Electroactive fibre-like micelles. The electroactive nature of the individual $r r \mathrm{P} 3 \mathrm{HT}-b-r s \mathrm{P} 3 \mathrm{HT}$ fibres was demonstrated using tunnelling AFM (TUNA) experiments, as depicted in Fig. 2a. Measurements were performed using the common bottom-contact architecture, with a $\mathrm{SiO}_{2}$ dielectric layer $(300 \mathrm{~nm})$, thermally evaporated $\mathrm{Au}$ electrodes $(30 \mathrm{~nm})$ and a hexamethyldisilazane layer (deposited by spin coating). Figure $2 \mathrm{~b}$ shows an AFM height image taken on several unfragmented $r r \mathrm{P} \mathrm{HT}_{106}-b-r s \mathrm{P}_{3} \mathrm{HT}_{47}$ fibre-like micelles (length $>10 \mu \mathrm{m}$ ) in the vicinity of a thermally evaporated gold electrode on a $\mathrm{Si} / \mathrm{SiO}_{2}$ substrate, as indicated by the black square in Fig. 2a. In this two-probe measurement, the Pt/Ir AFM tip and the evaporated gold were used as a pair of electrodes. The gold electrode, which is positioned at the bottom of the AFM images in Fig. 2, was not imaged to prevent a short circuit (see Supplementary Fig. 10 for the full AFM height image). The corresponding TUNA contact current image in Fig. $2 c$ shows a current map (in pA) upon the application of a constant DC bias of $9.0 \mathrm{~V}$, with the fibres clearly visible (see 'Characterization of TUNA samples' in the Supplementary Information). The maximum TUNA current measured was appreciable at $17.5 \mathrm{pA}$ (the scale of the TUNA current image in Fig. $2 \mathrm{c}$ is adjusted to $6 \mathrm{pA}$, to show the image more clearly), with the tip at a distance of $c a .100 \mathrm{~nm}$ from the electrode.

Field-effect transistors based on fibre-like micelles. The demonstration of conductivity for these fibres, which is significantly higher than that of the substrate, encouraged us to examine thin film assemblies of the uniform fibres with different lengths (and coronas) as active layers in organic field-effect transistors (OFETs). The OFET devices were prepared on the same substrates as used for TUNA measurements (Fig. 3a). Relatively long channel lengths $(L=30 \mu \mathrm{m}$ or longer) were used to reduce the contribution of contact resistance to the total resistance of the devices. The channel width was kept at $1 \mathrm{~mm}$ for all samples unless specified.

In our initial fabricated devices, solutions $\left(0.1 \mathrm{mg} \mathrm{ml}^{-1}\right)$ of unfragmented fibre-like micelles (length $>10 \mu \mathrm{m}$ ) prepared in anisole were deposited by spin-coating onto prepared substrates. Thin films with randomly oriented fibres (Fig. $3 b$ and Supplementary Fig. 11) with a thickness of a few fibre layers were prepared and tested (see 'Fabrication of GIWAXS, TUNA and OFET samples' in the Supplementary Information for further details).

Figure $3 \mathrm{c}$ shows typical output and transfer characteristics obtained from OFETs fabricated from pristine, unfragmented $r r \mathrm{P} 3 \mathrm{HT}_{106}-b-r s \mathrm{P}_{3} \mathrm{HT}_{47}$ fibres. The output curves clearly demonstrate the field effect with full channel saturation and negligible leakage. From the values of the square root of the saturation current (Fig. $3 \mathrm{~d}, V_{\mathrm{DS}}=-80 \mathrm{~V}$ ), we calculated the mobility $\mu$ to be $6.3 \times 10^{-3} \mathrm{~cm}^{2} \mathrm{~V}^{-1} \mathrm{~s}^{-1}$ (see 'Characterization of OFET samples' in the Supplementary Information). Meanwhile, OFETs from fully dissolved $r r \mathrm{P}_{3} \mathrm{HT}_{106}-b-r s \mathrm{P}_{3} \mathrm{HT}_{47}$ in chloroform (that is, without the pre-organized nanofibres), showed a much lower mobility $\left(1.9 \times 10^{-4} \mathrm{~cm}^{2} \mathrm{~V}^{-1} \mathrm{~s}^{-1}\right.$, see Supplementary Fig. 15).

To probe the influence of the corona on the mobility and performance of prepared OFETs, analogous studies were performed using unfragmented fibre-like micelles with a similar rrP3HT core and an insulating PS corona. A summary of mean field-effect mobility values (obtained over at least ten devices) for all of the materials investigated is shown in Table 1. We found that the OFETs from $r r \mathrm{P}_{3} \mathrm{HT}_{54}-b$ - $\mathrm{PS}_{44}$ fibres (Table 1, Entry 3) exhibited very similar $\mu$ values as those from $r r \mathrm{P} 3 \mathrm{HT}_{48}-b$-rs $\mathrm{P} 3 \mathrm{HT}_{43}$ fibres (Table 1, Entry 2). Considering the insulating nature of PS corona chains, this finding suggests that the $r s \mathrm{P} 3 \mathrm{HT}$ corona block makes a very small, if not negligible, contribution to the overall mobility in the fibres. We therefore believe that charge transport occurs through the crystalline $r r \mathrm{P} 3 \mathrm{HT}$ core (that is, intra-fibre) rather than through the amorphous corona chains. In an additional control experiment, devices made from films of amorphous $r s \mathrm{P}_{3} \mathrm{HT}_{90}$ homopolymer showed no measurable field effect, despite their semiconductive nature, providing further support for this assertion (Supplementary Fig. 14). The apparent independence of $\mu$ on the corona block is also supported by the observation of similar values of $\mu$ obtained from $r r \mathrm{P} \mathrm{HT}_{48}$ homopolymer fibre-based OFET devices (Table 1, Entry 1 ). These similar values of $\mu$ from $r r \mathrm{P}_{3} \mathrm{HT}_{48}-b$-rs $\mathrm{P}_{3} \mathrm{HT}_{43}$ fibres, $r r \mathrm{P} 3 \mathrm{HT}_{54}-b$ - $\mathrm{PS}_{44}$ fibres and $r r \mathrm{P}_{3} \mathrm{HT}_{48}$ homopolymer fibres clearly demonstrated that charge carrier mobility is independent of corona composition. Furthermore, on increasing the DP of the $r r$ P3HT block from 48 to 70 , and finally to $106, \mu$ also increased, regardless of the nature and length of the corona-forming block (Table 1). This increase is probably due to the higher electronic coupling along the conjugated chains and better-connected domains ${ }^{51}$. However, in contrast to the $\mathrm{BCP}$ fibres, those comprising solely $r \mathrm{P} 3 \mathrm{HT}$ homopolymer, without the steric protection of the solvated $r s \mathrm{P} 3 \mathrm{HT}$ corona chains, exhibited poor colloidal stability and precipitated from anisole.

With these results clearly indicating the dependence of mobility on $r r \mathrm{P} 3 \mathrm{HT}$ molar mass, we next explored the influence of overall fibre length (whilst keeping the molar mass constant). As a result of the ability to control the length of the fibres and to prepare samples with narrow length distributions through the described living CDSA self-seeding process, we prepared OFET devices with $r r \mathrm{P}_{3} \mathrm{HT}_{106}-b-r s \mathrm{P}_{3} \mathrm{HT}_{47}$ fibres of specific and predetermined dimensions. When the variation of saturation mobility was plotted against $r r \mathrm{P}_{3} \mathrm{HT}_{106}-b-r s \mathrm{P} 3 \mathrm{HT}_{47}$ fibre length, a strong, super-linear dependence was found (Fig. 4b), with mobility values ranging over two orders of magnitude, from $2.4 \times 10^{-5}$ to $4.4 \times 10^{-3} \mathrm{~cm}^{2} \mathrm{~V}^{-1} \mathrm{~s}^{-1}$. A similar relationship has been reported between the charge-carrier mobility and (crystal) grain sizes for OFETs based on pentacene ${ }^{52}$, copper phthalocyanine ${ }^{53}$ oligo(thiophene) $\mathrm{s}^{54}$ and P3HT crystals ${ }^{55}$. In all of these previously reported cases, the increase in mobility was attributed to a decreased density of grain boundaries. We therefore postulate that a process analogous to control over the density of grain boundaries takes place in our case. Here the increase in fibre length leads to an effective increase in the size of the grains. As all self-seeded fibres were randomly oriented and much shorter than the transistor channel length $(30$ or $50 \mu \mathrm{m})$, both fast intra- and slow inter-fibre charge transport have to be considered, as depicted schematically in Fig. 4a. In this case, controlling the fibre length can be equated to controlling the size of the grains in polycrystalline films of small organic molecules: longer fibres present an increase of grain size and thus an effective reduction in grain boundary density, leading to enhanced mobility. Furthermore, the observed super-linear charge-carrier mobility dependence on grain size fits well with previous models for both small molecules ${ }^{56}$ and thin films of crystallized P3HT ${ }^{55}$. Significantly, the hole mobility of uniform $950 \mathrm{~nm}$ fibres from $r r \mathrm{P}^{2} \mathrm{HT}_{106^{-}} b-r s \mathrm{P}_{3} \mathrm{HT}_{47} \quad\left(4.0 \times 10^{-3} \mathrm{~cm}^{2} \mathrm{~V}^{-1} \mathrm{~s}^{-1}\right)$ is higher than that from unfragmented $r r \mathrm{P}_{3} \mathrm{HT}_{48}-b-r s \mathrm{P}_{3} \mathrm{HT}_{43}$ 


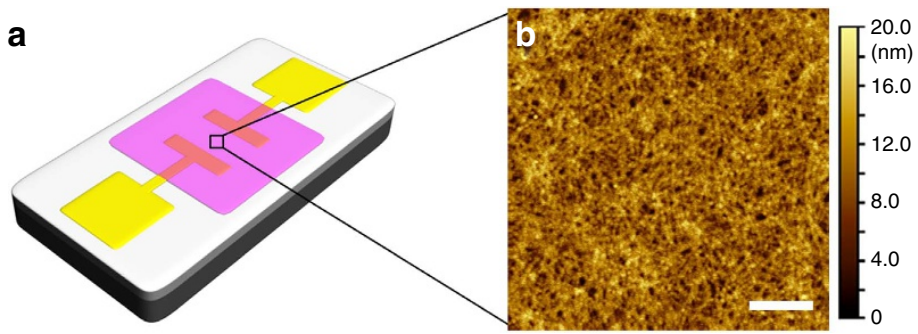

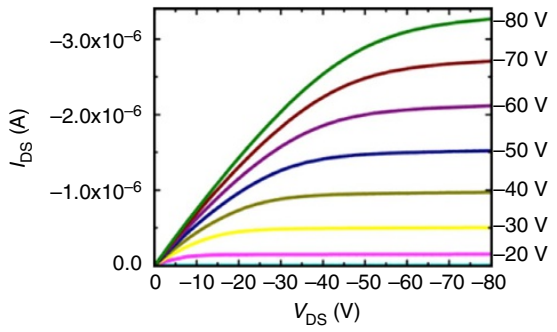

d

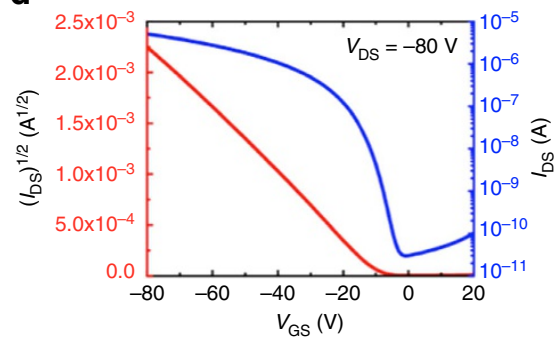

Figure 3 | OFETs fabricated from the rrP3HT-b-rsP3HT and rrP3HT-b-PS fibres. (a) Schematic illustration of the bottom-gate, bottom-contact OFET device (structures not drawn to scale; purple: semiconducting film; yellow: gold source/drain electrodes; light grey: dielectric $\mathrm{SiO}_{2}$ layer; dark grey: gate $\mathrm{Si}$ electrode). (b) AFM image of $r r \mathrm{P}_{3} \mathrm{HT}_{106}-b$-rs $\mathrm{PHHT}_{47}$ fibres (cast from $0.1 \mathrm{mg} \mathrm{ml}^{-1}$ anisole solution). Scale bar, $1 \mu \mathrm{m}$. The representative (c) output and (d) transfer characteristics of the OFET device of the unfragmented $r \mathrm{P}_{3} \mathrm{HT}_{106}-b$-rsP3HT 47 fibres $\left(L_{n}>10 \mu \mathrm{m}\right)\left(I_{\mathrm{DS}}=\right.$ drain-to-source current;

$V_{\mathrm{DS}}=$ drain-to-source bias; $V_{\mathrm{GS}}=$ gate-to-source bias).

\section{Table 1 | Mean field-effect mobility and on/off ratios obtained from at least ten devices for all unfragmented (length $>10 \mu \mathrm{m}$ ) fibres investigated in this work.}

\begin{tabular}{|c|c|c|}
\hline Fibre type & Mobility $\left(\times 10^{-3} \mathrm{~cm}^{2} \mathrm{v}^{-1} \mathrm{~s}^{-1}\right)$ & On/off ratio \\
\hline${\mathrm{rrP} 3 \mathrm{HT}_{48}}$ & $2.1 \pm 0.3$ & $5 \times 10^{4}$ \\
\hline$r r \mathrm{P} 3 \mathrm{HT}_{48}-b-r s \mathrm{P}_{3} \mathrm{HT}_{43}$ & $2.0 \pm 0.6$ & $5 \times 10^{5}$ \\
\hline $\mathrm{rrP}_{3} \mathrm{HT}_{54}-b-\mathrm{PS}_{44}$ & $1.7 \pm 0.2$ & $2 \times 10^{5}$ \\
\hline $\operatorname{rrP} \mathrm{HT}_{70}-b-\mathrm{PS}_{197}$ & $3.4 \pm 0.1$ & $8 \times 10^{4}$ \\
\hline${ }_{r r P} 3 \mathrm{HT}_{106}-b-r s \mathrm{P}_{3} \mathrm{HT}_{47}$ & $6.3 \pm 1.0$ & $2 \times 10^{5}$ \\
\hline
\end{tabular}

$\left(2.0 \times 10^{-3} \mathrm{~cm}^{2} \mathrm{~V}^{-1} \mathrm{~s}^{-1}\right)$. This mobility difference can once again be attributed to the molecular weight difference between the rrP3HT blocks. The intrachain transport contribution probably plays a far more significant role than the interchain transport, as is also supported by the mobility values obtained from unfragmented fibres $\left(L_{\mathrm{n}}>10 \mu \mathrm{m}\right): \quad r r \mathrm{P}_{3} \mathrm{HT}_{106}-b$ - $r s \mathrm{P}_{3} \mathrm{HT}_{47}$ $\left(6.3 \times 10^{-3} \mathrm{~cm}^{2} \mathrm{~V}^{-1} \mathrm{~s}^{-1}\right)$ and $\operatorname{rrP}^{-1 \mathrm{HT}_{48}}-b$-rs $\mathrm{P} 3 \mathrm{HT}_{43}$ $\left(2.0 \times 10^{-3} \mathrm{~cm}^{2} \mathrm{~V}^{-1} \mathrm{~s}^{-1}\right)$, respectively.

The mobility values obtained $\left(\mu \sim 10^{-3} \mathrm{~cm}^{2} \mathrm{~V}^{-1} \mathrm{~s}^{-1}\right)$ are comparable with those for early P3HT field-effect devices ${ }^{57,58}$, but are significantly lower than more recent and optimized systems ${ }^{59}\left(\mu \sim 10^{-1} \mathrm{~cm}^{2} \mathrm{~V}^{-1} \mathrm{~s}^{-1}\right)$. In general, improvements to overall device performance would be anticipated through similar optimization strategies that involve the use of high molar mass $\mathrm{P} \mathrm{HT}^{48,60}$, higher boiling point solvents ${ }^{61}$ or thin-film annealing procedures ${ }^{48,51}$. Furthermore, as it has been demonstrated that the alignment of carbon nanotubes ${ }^{62}$ and semiconductive polymer chains substantially enhances charge-carrier mobility ${ }^{27,63}$, alignment of the $\mathrm{BCP}$ fibres should also lead to increased mobilities.

Our preliminary results indicate this to be the case and unoptimized mobility values of over $1.5 \pm 0.16 \times 10^{-2} \mathrm{~cm}^{2} \mathrm{~V}^{-1}$ $\mathrm{s}^{-1}$ were achievable using alignment via a dip-coating procedure. An AFM image of the aligned unfragmented $r \mathrm{P}^{2} \mathrm{HT}_{106}-b-r s \mathrm{P}_{3} \mathrm{HT}_{47}$ fibres is shown in Fig. $4 \mathrm{c}$ and the transfer curves from the corresponding FET device in Fig. 4d. With this dip-coating procedure, most of the micelles were aligned between the two electrodes (for experimental details and more characterization of the sample, see 'Preparation and testing of OFET with aligned fibres' in the Supplementary Information and Supplementary Fig. 13). Clearly, this alignment greatly enhanced the charge-carrier mobility (which increased from $6.3 \times 10^{-3}$ to $1.5 \times 10^{-2} \mathrm{~cm}^{2} \mathrm{~V}^{-1} \mathrm{~s}^{-1}$ ). In addition to the wide range of alignment conditions available, the control over fibre length, corona type and, finally, type of semiconducting core material, provides a myriad of potential opportunities for further improvement in device performance. The mobility enhancement after alignment (ca. 140\%) is encouraging and further investigations to improve hole mobility are ongoing and will be reported in the near future.

\section{Discussion}

In summary, fibre-like micelles with a well-defined core-corona structure prepared from a $\pi$-conjugated BCP have been shown to possess promising electroactive properties in single-fibre TUNA-AFM investigations. Their preparation by the living CDSA self-seeding method yields low dispersity samples with finely controlled lengths and excellent colloidal stability provided by the corona chains, which has allowed a detailed evaluation of their performance in bottom-contact field-effect transistors. The charge-carrier mobilities are independent of corona composition, increase with molar mass of the electroactive core-forming block and, more importantly, also increase in a super-linear manner with fibre length. Although the mobility values in this proof-of-concept work were relatively modest, obvious future avenues exist for the improvement of device performance as shown by the values obtained from aligned-fibre devices. Moreover, as the versatile living CDSA method should be applicable to other crystallizable $\pi$-conjugated semiconducting polymers (and other corona blocks), opportunities exist for the incorporation of a wide range of uniform electroactive micelle-based nanostructures into devices, including more 
a

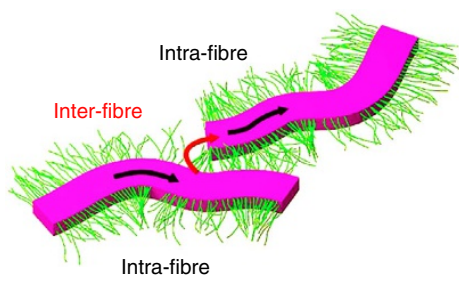

C

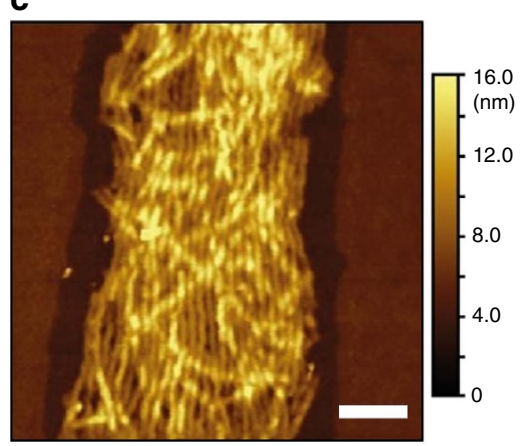

b

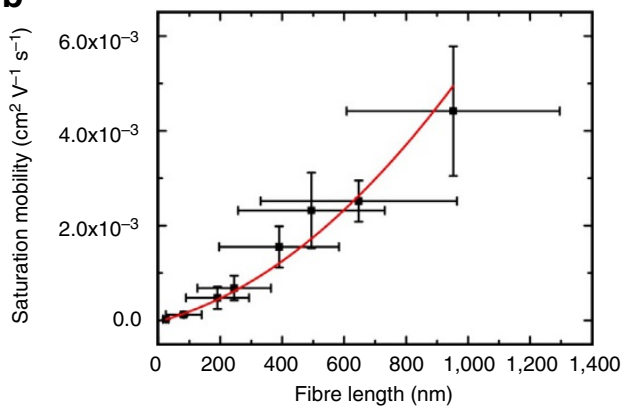

d

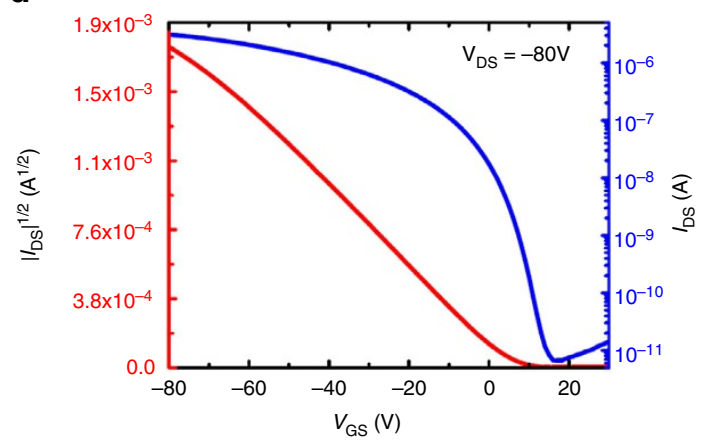

Figure 4 | Field-effect mobility of devices from $\boldsymbol{r r P}_{\mathbf{3}} \mathbf{H T}_{\mathbf{1 0 6}} \mathbf{- b}-\mathbf{r s} \mathbf{P} \mathbf{3} \mathbf{H T}_{\mathbf{4 7}}$ fibres. (a) Schematic illustration of the charge-carrier transfer processes present in thin films of semiconductive fibre networks. (b) Variation of saturation mobility versus the fibre lengths after self-seeding. The red curve is a quadratic fit to the data. Each saturation mobility data point is averaged over the data from at least ten devices. (c) AFM image of the aligned and unfragmented $r_{\mathrm{PP} 3 \mathrm{HT}_{106}}-b$-rsP3HT 47 fibres $\left(L_{n}>10 \mu \mathrm{m}\right)$. Scale bar, $200 \mathrm{~nm}$. (d) Transfer characteristics of the OFET device of the aligned and unfragmented $r \mathrm{P} \mathrm{HT}_{106^{-}} b-$ rsP3HT 47 fibres.

complex architectures such as segmented structures ${ }^{38,64}$ or micelle-nanoparticle hybrids ${ }^{12,13,65,66}$.

\section{Methods}

Materials. Methanol (MeOH), hexane, anisole, 1,2-dichlorobenzene, 2,5-dibromo3-hexylthiophene, chloroform, lithium chloride $(\mathrm{LiCl})$, [1,3-bis(diphenylphosphino)propane]dichloronickel(II) $\left(\mathrm{Ni}(\mathrm{dppp}) \mathrm{Cl}_{2}\right)$ and tert-butylmagnesium chloride $(1.0 \mathrm{M}$ in tetrahydrofuran (THF)) were purchased from Sigma-Aldrich and used as received. 5, $5^{\prime}$-Dibromo-3, $3^{\prime}$-dihexyl-2,2' -bithiophene was purchased from Tokyo Chemical Industry and used as received. Cyclohexane and THF were purchased from Fisher Scientific. THF for polymerizations was distilled over sodium and benzophenone before use. Hexamethyldisilazane (electronic grade) was purchased from Alfa Aesar and was used as received. Octadecyltrichlorosilane was purchased from Acros Organics.

Synthesis of $r$ P3HT-b-rsP3HT. The diblock copolymers were synthesized via sequential polymerization of the two monomers, 2,5-dibromo-3-hexylthiophene and 5,5'-dibromo-3,3'-dihexyl-2,2'-bithiophene via the GRIM method ${ }^{67-69}$. For a typical synthesis route for $r r P 3 \mathrm{HT}_{48}-b$-rs $\mathrm{P}_{3} \mathrm{HT}_{43}, 2,5$-dibromo-3-hexylthiophene (324 mg, $1 \mathrm{mmol}$ ) (solution 1) and 5,5'-dibromo-3,3'-dihexyl -2,2' -bithiophene ( $246 \mathrm{mg}, 0.5 \mathrm{mmol}$ ) (solution 2) were dispersed into $5 \mathrm{ml}$ of THF in two separate vials. tert-Butylmagnesium bromide solution (1 eq. mol to the monomer) was added dropwise into the two solutions. Both solutions were stirred for $2 \mathrm{~h}$ in the dark. Another $20 \mathrm{ml}$ of THF was added into solution 1 before $10.8 \mathrm{mg}(0.02 \mathrm{mmol}$, $2 \% \mathrm{~mol}$ ) of $\mathrm{Ni}(\mathrm{dppp}) \mathrm{Cl}_{2}$ was added in one portion. After $30 \mathrm{~min}$ of stirring, solution 2 was added into solution 1 and the resultant mixture was allowed to stir overnight. The reaction was quenched by adding $\mathrm{HCl}$ aqueous solution (5\%). (All the reactions, except the quenching, were conducted at room temperature $\left(23^{\circ} \mathrm{C}\right)$ and in a glove box under $\mathrm{Ar}$ atmosphere $\left(\mathrm{O}_{2}\right.$ and $\mathrm{H}_{2} \mathrm{O}$ level <2 p.p.m.). Chloroform $(100 \mathrm{ml})$ and $\mathrm{H}_{2} \mathrm{O}(50 \mathrm{ml})$ were added into the solution and the polymer was extracted into organic layer. The organic layer was separated and dried under vacuum. The solid was then purified by Soxhlet extraction, using $\mathrm{MeOH}$ and hexane as solvent. The purified polymer was collected by dissolving in chloroform, concentrating under vacuum, precipitating into $\mathrm{MeOH}$ and obtained by centrifugation. The diblock copolymers were further fractionated by passing through a size exclusion chromatography column with THF as eluent. A soft dark purple solid (103 mg) was obtained with a yield of $18 \%$. The synthesis of $r r \mathrm{P} 3 \mathrm{HT}-b$ PS has been described elsewhere $\mathrm{e}^{38}$ and is not repeated here. The $\mathrm{Cu}$ salt was removed by passing through basic alumina and silica gel columns repeatedly. Based on the elemental analysis results (graphite furnace atomic absorption), the content of $\mathrm{Cu}$ content is very low, at the p.p.m. level, and would not influence the FET device performance significantly ${ }^{70}$. For characterization data, see Supplementary Table 1 .

Polymer characterization. Gel permeation chromatography was carried out on a Viscotek VE 2001 Triple-Detector Gel Permeation Chromatograph equipped with an automatic sampler, a pump, an injector, an inline degasser and a column oven $\left(30^{\circ} \mathrm{C}\right)$. The elution columns consist of styrene/divinyl benzene gels with pore sizes of $500 \AA$ and $100,000 \AA$. Detection was conducted by means of a VE 3580 refractometer, a four-capillary differential viscometer, and $90^{\circ}$ and low angle $\left(7^{\circ}\right)$ laser light $\left(\lambda_{0}=670 \mathrm{~nm}\right)$ scattering detectors, VE 3210 and VE 270 . THF was used as the eluent, with a flow rate of $1.0 \mathrm{ml} \mathrm{min}^{-1}$. Samples were dissolved in THF $\left(2 \mathrm{mg} \mathrm{ml}^{-1}\right)$ and filtered with a Ministart SRP 15 filter (polytetrafluoroethylene membrane of $0.45 \mu \mathrm{m}$ pore size) before analysis. The calibration was conducted using a PolyCALPS standard from Viscotek. To determine the molecular weight of the BCPs, aliquots of the first block were taken and the absolute molecular weight of the first block was determined by matrix-assisted laser desorption/ionizationtime of flight mass spectrometry. The absolute polymerization degrees of the two blocks were then determined by combining the molecular weight $M_{\mathrm{n}}$ of the first block from matrix-assisted laser desorption/ionization-time of flight mass spectrometry measurements with the block ratio of the diblock copolymer obtained by integration of the ${ }^{1} \mathrm{H}$ NMR spectrum. The regioregularities of the polymers were determined from their ${ }^{1} \mathrm{H}$ NMR spectra. The differential scanning calorimetry and thermogravimetric analyses were performed on the Q100 and Q500 from TA instruments at heating/cooling rates of $10^{\circ} \mathrm{C} \mathrm{min}-1$. The differential scanning calorimeter was coupled to a refrigerated cooling system (RCS90).

Self-assembly of rrP3HT-b-rsP3HT in solvents. Typically, the diblock copolymers were directly dispersed into anisole at a concentration of $1 \mathrm{mg} \mathrm{ml}^{-1}$ in tightly sealed vials. The solution was heated at $80^{\circ} \mathrm{C}$ for $2 \mathrm{~h}$ without stirring before cooling down to room temperature. The solutions were bright orange at high temperatures and turned purple in several hours after cooling to room temperature. The $r r$ P3HT- $b$-PS fibres were prepared by exactly the same method. Fibres from $r r \mathrm{P}_{3} \mathrm{HT}_{48}$ homopolymer were prepared in the same way as the diblock copolymers, except that the fibres were not quite colloidally stable and a precipitate was formed after storage at room temperature for several days. All the pristine fibres formed by the diblock copolymers and homopolymer were longer than $10 \mu \mathrm{m}$ and were polydisperse in length. 


\section{Preparation of fibres with controlled length via the self-seeding method.}

Fibres prepared in anisole (after 2 days of ageing at $23^{\circ} \mathrm{C}$ ) were subjected to sonication in a sonication bath $(160 \mathrm{~W})$ at $0{ }^{\circ} \mathrm{C}$ for $60 \mathrm{~min}$ to yield seed fibres. The seed solution was heated at different temperatures for $30 \mathrm{~min}$ then cooled and aged at room temperature to allow the nanofibres to grow.

It is worth noting that the self-seeding window for $r r \mathrm{P}_{3} \mathrm{HT}_{106}-b-r s \mathrm{P}_{3} \mathrm{HT}_{47}$ fibres is much higher and narrower than that for the $r r \mathrm{P}_{3} \mathrm{HT}_{48}-b-r s \mathrm{P}_{3} \mathrm{HT}_{43}$ fibres. This can be better appreciated by plotting the length of the fibres versus annealing temperatures, as shown in Fig. $1 \mathrm{~g}$ and Supplementary Fig. 9f. We believe that this difference can be attributed to the much higher DP of the $r r \mathrm{P} 3 \mathrm{HT}$ block for $r r \mathrm{P} \mathrm{HT}_{106}-b-r s \mathrm{P}_{3} \mathrm{HT}_{47}$, resulting in higher crystallinity of the fibres. This was supported by the more significant red-shift of the ultraviolet-visible absorbance spectra of the nanofibre solution from $r r \mathrm{P}^{2} \mathrm{HT}_{106}-b-r s \mathrm{P}_{3} \mathrm{HT}_{47}$, as shown in Supplementary Fig. 6.

Data availability. All data are available from the authors upon reasonable request.

\section{References}

1. Mai, Y. \& Eisenberg, A. Self-assembly of block copolymers. Chem. Soc. Rev. 41, 5969-5985 (2012)

2. Geng, Y. et al. Shape effects of filaments versus spherical particles in flow and drug delivery. Nat. Nanotechnol. 2, 249-255 (2007).

3. Zheng, R., Liu, G., Devlin, M., Hux, K. \& Jao, T. Friction reduction of lubricant base oil by micelles and crosslinked micelles of block copolymers. Tribol. Trans. 53, 97-107 (2009)

4. Liu, J. et al. Toughening of epoxies with block copolymer micelles of wormlike morphology. Macromolecules 43, 7238-7243 (2010).

5. Gould, O. E. C. et al. Transformation and patterning of supermicelles using dynamic holographic assembly. Nat. Commun. 6, 10009 (2015).

6. Tu, G. L. et al. Amphiphilic conjugated block copolymers: synthesis and solvent-selective photoluminescence quenching. Small 3, 1001-1006 (2007).

7. Baghgar, M. et al. Morphology-dependent electronic properties in cross-linked (P3HT-b-P3MT) block copolymer nanostructures. ACS Nano 8, 8344-8349 (2014)

8. Kamps, A. C., Fryd, M. \& Park, S. J. Hierarchical self-assembly of amphiphilic semiconducting polymers into isolated, bundled, and branched nanofibers. ACS Nano 6, 2844-2852 (2012).

9. Lee, E. et al. Hierarchical helical assembly of conjugated poly(3hexylthiophene)-block-poly(3-triethylene glycol thiophene) diblock copolymers. J. Am. Chem. Soc. 133, 10390-10393 (2011).

10. Lee, I.-H. et al. Nanostar and nanonetwork crystals fabricated by in situ nanoparticlization of fully conjugated polythiophene diblock copolymers. J. Am. Chem. Soc. 135, 17695-17698 (2013).

11. Lee, I.-H. \& Choi, T.-L. Importance of choosing the right polymerization method for in situ preparation of semiconducting nanoparticles from the P3HT block copolymer. Polym. Chem. 7, 7135-7141 (2016).

12. Jin, S.-M., Kim, I., Lim, J. A., Ahn, H. \& Lee, E. Interfacial crystallization-driven assembly of conjugated polymers/quantum dots into coaxial hybrid nanowires: elucidation of conjugated polymer arrangements by electron tomography. $A d v$. Funct. Mater. 26, 3226-3235 (2016).

13. Kim, Y.-J. et al. Precise control of quantum dot location within the P3HT-bP2VP/QD nanowires formed by crystallization-driven 1D growth of hybrid dimeric seeds. J. Am. Chem. Soc. 136, 2767-2774 (2014).

14. Cativo, M. H. M. et al. Air-liquid interfacial self-assembly of conjugated block copolymers into ordered nanowire arrays. ACS Nano 8, 12755-12762 (2014).

15. Ren, G. Q., Wu, P.-T. \& Jenekhe, S. A. Solar cells based on block copolymer semiconductor nanowires: effects of nanowire aspect ratio. ACS Nano $\mathbf{5}$, 376-384 (2011).

16. Brabec, C. J., Sariciftci, N. S. \& Hummelen, J. C. Plastic solar cells. Adv. Funct. Mater. 11, 15-26 (2001)

17. Günes, S., Neugebauer, H. \& Sariciftci, N. S. Conjugated polymer-based organic solar cells. Chem. Rev. 107, 1324-1338 (2007).

18. Gao, D., Hollinger, J. \& Seferos, D. S. Selenophene-thiophene block copolymer solar cells with thermostable nanostructures. ACS Nano 6, 7114-7121 (2012).

19. Grimsdale, A. C., Chan, K. L., Martin, R. E., Jokisz, P. G. \& Holmes, A. B. Synthesis of light-emitting conjugated polymers for applications in electroluminescent devices. Chem. Rev. 109, 897-1091 (2009).

20. Park, S. J., Kang, S. G., Fryd, M., Saven, J. G. \& Park, S. J. Highly tunable photoluminescent properties of amphiphilic conjugated block copolymers. J. Am. Chem. Soc. 132, 9931-9933 (2010).

21. Gill, R. E., Malliaras, G. G., Wildeman, J. \& Hadziioannou, G. Tuning of photo- and electroluminescence in alkylated polythiophenes with well-defined regioregularity. Adv. Mater. 6, 132-135 (1994).

22. Dimitrakopoulos, C. D. \& Malenfant, P. R. L. Organic thin film transistors for large area electronics. Adv. Mater. 14, 99-117 (2002).

23. Sirringhaus, H. Organic field-effect transistors: the path beyond amorphous silicon. Adv. Mater. 26, 1319-1335 (2014).
24. Yap, B. K., Xia, R., Campoy-Quiles, M., Stavrinou, P. N. \& Bradley, D. D. C. Simultaneous optimization of charge-carrier mobility and optical gain in semiconducting polymer films. Nat. Mater. 7, 376-380 (2008).

25. Thomas, S. W. III, Joly, G. D. \& Swager, T. M. Chemical sensors based on amplifying fluorescent conjugated polymers. Chem. Rev. 107, 1339-1386 (2007).

26. McQuade, D. T., Pullen, A. E. \& Swager, T. M. Conjugated polymer-based chemical sensors. Chem. Rev. 100, 2537-2574 (2000).

27. Briseno, A. L., Mannsfeld, S. C. B., Jenekhe, S. A., Bao, Z. \& Xia, Y. Introducing organic nanowire transistors. Mater. Today 11, 38-47 (2008).

28. Wang, S. et al. Organic field-effect transistors based on highly ordered single polymer fibers. Adv. Mater. 24, 417-420 (2012).

29. Xiao, C. et al. High performance polymer nanowire field-effect transistors with distinct molecular orientations. Adv. Mater. 27, 4963-4968 (2015).

30. Yu, Z. et al. Self-assembly of well-defined poly(3-hexylthiophene) nanostructures toward the structure-property relationship determination of polymer solar cells. J. Phys. Chem. C 116, 23858-23863 (2012).

31. Choi, D., Chang, M. \& Reichmanis, E. Controlled assembly of poly(3-hexylthiophene): managing the disorder to order transition on the nano- through meso-scales. Adv. Funct. Mater. 25, 920-927 (2015).

32. Qiu, Y. et al. Synthesis of polyfuran and thiophene-furan alternating copolymers using catalyst-transfer polycondensation. ACS Macro Lett. 5, 332-336 (2016).

33. Wudl, F. et al. Synthesis and characterization of two regiochemically defined poly(dialkylbithiophenes): a comparative study. Macromolecules 23, 1268-1279 (1990).

34. Osaka, I. \& McCullough, R. D. Advances in molecular design and synthesis of regioregular polythiophenes. Acc. Chem. Res. 41, 1202-1214 (2008).

35. Zhang, Y., Tajima, K., Hirota, K. \& Hashimoto, K. Synthesis of all-conjugated diblock copolymers by quasi-living polymerization and observation of their microphase separation. J. Am. Chem. Soc. 130, 7812-7813 (2008).

36. Scherf, U., Gutacker, A. \& Koenen, N. All-conjugated block copolymers. Acc. Chem. Res. 41, 1086-1097 (2008).

37. Gwyther, J. et al. Dimensional control of block copolymer nanofibers with a $\pi$-conjugated core: crystallization-driven solution self-assembly of amphiphilic poly(3-hexylthiophene)-b-poly(2-vinylpyridine). Chem. A Eur. J. 19, 9186-9197 (2013).

38. Qian, J. S. et al. Uniform, high aspect ratio fiber-like micelles and block co-micelles with a crystalline $\pi$-conjugated polythiophene core by self-seeding J. Am. Chem. Soc. 136, 4121-4124 (2014).

39. Gilroy, J. B. et al. Monodisperse cylindrical micelles by crystallization-driven living self-assembly. Nat. Chem. 2, 566-570 (2010).

40. Wang, X. et al. Cylindrical block copolymer micelles and co-micelles of controlled length and architecture. Science 317, 644-647 (2007).

41. Qian, J. S. et al. Self-seeding in one dimension: an approach to control the length of fiberlike polyisoprene-polyferrocenylsilane block copolymer micelles. Angew. Chem. Int. Ed. 50, 1622-1625 (2011).

42. Qian, J. S. et al. Self-seeding in one dimension: a route to uniform fiber-like nanostructures from block copolymers with a crystallizable core-forming block. ACS Nano 7, 3754-3766 (2013).

43. Bassett, D. C. Principles of Polymer Morphology. (Cambridge Univ. Press, 1981)

44. Rahimi, K. et al. Controllable processes for generating large single crystals of poly(3-hexylthiophene). Angew. Chem. Int. Ed. 51, 11131-11135 (2012).

45. Li, B. \& Li, C. Y. Immobilizing Au nanoparticles with polymer single crystals, patterning and asymmetric functionalization. J. Am. Chem. Soc. 129, 12-13 (2007).

46. Huang, W., Luo, C., Zhang, J., Yu, K. \& Han, Y. Tethered diblock copolymer chains on platelets prepared by semicrystalline $\mathrm{ABC}$ triblock copolymers in toluene with trace amounts of water. Macromolecules 40, 8022-8030 (2007).

47. Brinkmann, M. \& Rannou, P. Molecular weight dependence of chain packing and semicrystalline structure in oriented films of regioregular poly(3-

hexylthiophene) revealed by high-resolution transmission electron microscopy Macromolecules 42, 1125-1130 (2009).

48. Zen, A. et al. Effect of molecular weight and annealing of poly(3hexylthiophene)s on the performance of organic field-effect transistors. $A d v$. Funct. Mater. 14, 757-764 (2004).

49. Xu, J., Ma, Y., Hu, W., Rehahn, M. \& Reiter, G. Cloning polymer single crystals through self-seeding. Nat. Mater. 8, 348-353 (2009).

50. Baghgar, M. et al. Effect of polymer chain folding on the transition from $\mathrm{H}-$ to J-aggregate behavior in P3HT nanofibers. J. Phys. Chem. C 118, 2229-2235 (2014).

51. Noriega, R. et al. A general relationship between disorder, aggregation and charge transport in conjugated polymers. Nat. Mater. 12, 1038-1044 (2013).

52. Di Carlo, A., Piacenza, F., Bolognesi, A., Stadlober, B. \& Maresch, H. Influence of grain sizes on the mobility of organic thin-film transistors. Appl. Phys. Lett. 86, 1-3 (2005).

53. Qian, C. et al. Crystal-domain orientation and boundary in highly ordered organic semiconductor thin film. J. Phys. Chem. C 119, 14965-14971 (2015). 
54. Horowitz, G. \& Hajlaoui, M. E. Mobility in polycrystalline oligothiophene field-effect transistors dependent on grain size. Adv. Mater. 12, 1046-1050 (2000).

55. Crossland, E. J. W. et al. Anisotropic charge transport in spherulitic poly(3-hexylthiophene) films. Adv. Mater. 24, 839-844 (2012).

56. Wo, S., Headrick, R. L. \& Anthony, J. E. Fabrication and characterization of controllable grain boundary arrays in solution-processed small molecule organic semiconductor films. J. Appl. Phys. 111, 1-12 (2012).

57. Yoshino, K., Takahashi, H., Muro, K., Ohmori, Y. \& Sugimoto, R. Optically controlled characteristics of Schottky gated poly(3-alkylthiophene) field effect transistor. J. Appl. Phys. 70, 5035 (1991).

58. Assadi, A., Svensson, C., Willander, M. \& Inganäs, O. Field-effect mobility of poly(3-hexylthiophene). Appl. Phys. Lett. 53, 195-197 (1988).

59. Sirringhaus, H. et al. Two-dimensional charge transport in self-organized, high-mobility conjugated polymers. Nature 401, 685-688 (1999).

60. Kline, R. J., McGehee, M. D., Kadnikova, E. N., Liu, J. \& Fréchet, J. M. J. Controlling the field-effect mobility of regioregular polythiophene by changing the molecular weight. Adv. Mater. 15, 1519-1522 (2003).

61. Clark, J., Silva, C., Friend, R. H. \& Spano, F. C. Role of intermolecular coupling in the photophysics of disordered organic semiconductors: aggregate emission in regioregular polythiophene. Phys. Rev. Lett. 98, 206406 (2007).

62. Part, S. et al. Large-area assembly of densely aligned single-walled carbon nanotubes using solution shearing and their application to field-effect transistors. Adv. Mater. 27, 2656-2662 (2015).

63. Skrypnychuk, V. et al. Ultrahigh mobility in an organic semiconductor by vertical chain alignment. Adv. Mater. 28, 2359-2366 (2016).

64. Gädt, T., Ieong, N. S., Cambridge, G., Winnik, M. A. \& Manners, I. Complex and hierarchical micelle architectures from diblock copolymers using living, crystallization-driven polymerizations. Nat. Mater. 8, 144-150 (2009).

65. Wang, H. et al. Cylindrical block co-micelles with spatially selective functionalization by nanoparticles. J. Am. Chem. Soc. 129, 12924-12925 (2007).

66. Wang, H. et al. Fabrication of continuous and segmented polymer/metal oxide nanowires using cylindrical micelles and block comicelles as templates. Adv. Mater. 21, 1805-1808 (2009).

67. Jeffries-EL, M., Sauvé, G. \& McCullough, R. D. In-situ end-group functionalization of regioregular poly(3-alkylthiophene) using the grignard metathesis polymerization method. Adv. Mater. 16, 1017-1019 (2004)

68. Jeffries-El, M., Sauvé, G. \& McCullough, R. D. Facile synthesis of end-functionalized regioregular poly(3-alkylthiophene)s via modified Grignard metathesis reaction. Macromolecules 38, 10346-10352 (2005).

69. Loewe, R. S., Khersonsky, S. M. \& McCullough, R. D. A simple method to prepare head-to-tail coupled, regioregular poly(3-alkylthiophenes) using Grignard metathesis. Adv. Mater. 11, 250-253 (1999).

70. Usluer, ö. et al. Metal residues in semiconducting polymers: impact on the performance of organic electronic devices. ACS Macro Lett. 3, 1134-1138 (2014).

\section{Acknowledgements}

X.L. is grateful to the European Union (EU) for a Marie Curie Postdoctoral Fellowship. I.M. thanks the EPSRC for support through grant number EP/K017799/1. P.J.W. and O.E.C.G. acknowledge EPSRC funding through the Bristol Centre for Functional
Nanomaterials (BCFN, grant number EP/G036780/1). PeakForce AFM (carried out in the Chemical Imaging Facility, University of Bristol) was purchased under EPSRC Grant reference EP/K035746/1. T.S. gratefully acknowledges funding by the Alexander von Humboldt Foundation. Mass spectrometric analysis was performed on instrumentation bought through EPSRC grant (EP/K03927X/1). We thank Professor A. P. Davis for the use of a fluorescence spectrometer. We are also grateful to Professor Martin Kuball, Professor Michael Uren and the Centre for Device Thermography and Reliability, School of Physics, University of Bristol for technical help and useful suggestions.

\section{Author contributions}

The project was conceived and designed by X.L., P.J.W., C.F.J.F. and I.M. The experimental results were obtained by X.L., P.J.W., L.R.M., R.L.H. and T.G.D. X.L. and L.R.M. were responsible for materials synthesis, T.S. and H.F. for help and suggestions with substrate patterning and dip-coating, P.J.W. for OFET fabrication, characterization and AFM, R.L.H. for AFM and TUNA, whereas T.G.D. collected the GIWAXS data. J. R. and M. C. provided input on OFET characterisation and experimental design. The manuscript was written by X.L., P.J.W., C.F.J.F. and I.M. with useful input by the other co-authors. The project was supervised by C.F.J.F. and I.M.

\section{Additional information}

Supplementary Information accompanies this paper at http://www.nature.com/ naturecommunications

Competing interests: The authors declare no competing financial interests.

Reprints and permission information is available online at http://npg.nature.com/ reprintsandpermissions/

How to cite this article: $\mathrm{Li}, \mathrm{X}$. et al. Uniform electroactive fibre-like micelle nanowires for organic electronics. Nat. Commun. 8, 15909 doi: 10.1038/ncomms15909 (2017).

Publisher's note: Springer Nature remains neutral with regard to jurisdictional claims in published maps and institutional affiliations.

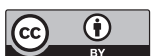

Open Access This article is licensed under a Creative Commons Attribution 4.0 International License, which permits use, sharing, adaptation, distribution and reproduction in any medium or format, as long as you give appropriate credit to the original author(s) and the source, provide a link to the Creative Commons license, and indicate if changes were made. The images or other third party material in this article are included in the article's Creative Commons license, unless indicated otherwise in a credit line to the material. If material is not included in the article's Creative Commons license and your intended use is not permitted by statutory regulation or exceeds the permitted use, you will need to obtain permission directly from the copyright holder. To view a copy of this license, visit http://creativecommons.org/ licenses/by/4.0/

(C) The Author(s) 2017 


\title{
Erratum: Uniform electroactive fibre-like micelle nanowires for organic electronics
}

\author{
Xiaoyu Li, Piotr J. Wolanin, Liam R. MacFarlane, Robert L. Harniman, Jieshu Qian, Oliver E.C. Gould, \\ Thomas G. Dane, John Rudin, Martin J. Cryan, Thomas Schmaltz, Holger Frauenrath, Mitchell A. Winnik,
} Charl F.J. Faul \& Ian Manners

Nature Communications 8:15909 doi: 10.1038/ncomms15909 (2017); Published 26 Jun 2017; Updated 27 Jul 2017.

An incorrect version of the Supplementary Information was inadvertently published with this Article where the wrong file was included. The Article has been updated to include the correct version of the Supplementary Information.

Open Access This article is licensed under a Creative Commons Attribution 4.0 International License, which permits use, sharing, adaptation, distribution and reproduction in any medium or format, as long as you give appropriate credit to the original author(s) and the source, provide a link to the Creative Commons license, and indicate if changes were made. The images or other third party material in this article are included in the article's Creative Commons license, unless indicated otherwise in

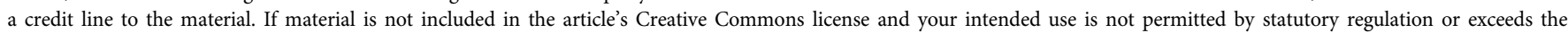
permitted use, you will need to obtain permission directly from the copyright holder. To view a copy of this license, visit http://creativecommons.org/licenses/by/4.0/

(C) The Author(s) 2017 